\title{
EL ESTATUTO DEL ENTENDIMIENTO AGENTE EN LA OBRA DE SAN ALBERTO MAGNO
}

\author{
José Ángel García-Cuadrado \\ Universidad de Navarra
}

\begin{abstract}
RESUMEN
El monopsiquismo averroísta no podía ser incorporado al pensamiento cristiano por oscurecer la idea de la inmortalidad del alma personal. Alberto Magno, intenta realizar una difícil síntesis de las doctrinas árabes y la teoría de la iluminación agustiniana. El resultado es una propuesta —no sistematizada- pero donde es posible advertir la distinción a nivel personal entre entendimiento agente y posible, de manera análoga a la distinción esencia/acto de ser.
\end{abstract}

Palabras clave: Alberto Magno, entendimiento agente, Dios, monopsiquismo.

\begin{abstract}
The Averroistic Monopsychism could not be incorporated to the Christian thought to darken the idea of the immortality of the personal soul. Albert the Great, tries to make a synthesis of the Arab doctrines and the Doctrine of Divine Illumination. The conclusion is a proposal - not systematize - but where it is possible to found the distinction at personal level between intellect agent and possible intellect, in analogous way to the distinction essence/act of being.
\end{abstract}

Key words: Albert the Great, agent intellect, God, Monopsychism.

Tomas Le Myesièr, discípulo de Ramón Llull, elaboró a comienzos del siglo XIV una antología de textos lulianos titulada Breviculum seu Electorium parvum Thomae Migerii o Breviculum ex Artibus Raimundi electum. En esta obra se respira el ambiente antiaverroísta propio de la época como consecuencia de las condenas del obispo Tempier en 1277 de algunas tesis averroístas. Para ilustrar el contenido de las disputas de Llull contra los averroístas, Le Myèsièr encargó doce miniaturas en donde se representaba, de manera alegórica, cuál debía ser la actitud del caballero cristiano para combatir con las armas de la razón al infiel. Esas miniaturas constituyen sin duda un valioso documento "gráfico» de la época: es una síntesis de la cultura universitaria simbolizada por los instrumentos dialécticos, las fórmulas en que resume las doctrinas y el estilo con el que retrata a los oponentes.

En la sexta minitaura se representa al ejército de Aristóteles (montado en un caballo blanco que lleva por nombre Ratiotinatio) seguido por su Comentador Averroes (con caballo negro, por nombre Imaginatio) asediando la torre de la falsedad (coronada por la opinión) donde se encuentra confinada la verdad que clama por su liberación. En el asta de este segundo caballero (Averroes) se lee: «la luz del entendimiento (agente) se manifiesta en la naturaleza como la luz del sol nos permite ver en la oscuridad». En el carro llevado por éste último caballo se encuentran varios personajes, entre ellos un alto eclesiástico que se lamenta y discute con el Comentador sobre el entendimiènto agente: «no podemos superar las imágenes que abstraemos 
de la naturaleza, por ello cada vez que intento entender está como un obstáculo tu intelecto (agente), Averroes» ${ }^{1}$.

Quizás no puedan expresarse de manera más plástica los recelos y dificultades que la doctrina monopsiquista de Averroes despertó en la Universidad de París y provocó la promulgación del Syllabus. Según éste, quienes siguen al Comentarista creen que existe un mismo intelecto para todos los hombres; ese intelecto universal permite que las abstracciones de la imaginación, sacadas del contacto con la naturaleza, se conviertan en ideas generales (y por tanto, en ciencia). Pero aceptar esta noción de intelecto agente afecta no sólo al conocimiento, sino también a la concepción del alma humana y su relación con Dios. La felicidad humána consistiría en la unión con el entendimiento universal pero dejando en entredicho la pervivencia del alma individual.

Para la adecuada recepción de la doctrina aristotélica era preciso reformular la doctrina averroista acerca del entendimiento único y universal. San Alberto Magno y Santo Tomás de Aquino fueron los primeros en sostener la existencia de un entendimiento agente (y paciente) en cada hombre. De manera análoga a como Aristóteles «bajó» al mundo sublunar las ideas platónicas, estos dos dominicos medievales «bajaron», cada uno a su manera, el entendimiento agente al ámbito de la persona humana. Pero como en el caso del Estagirita, ese cambio de perspectiva supuso una alteración total de la gnoseología y antropología de su tiempo.

\section{EL MONOPSIQUISMO AVERROISTA}

La interpretación de Averroes sobre el entendimiento agente recoge en parte la doctrina legada por sus predecesores ${ }^{2}$. Esto es lo que parece desprenderse de las primeras obras del filósofo cordobés - Epitome de Metafísica y las Parva Naturalia- en las que adopta una cosmovisión neoplatónica. Sigue la explicación de Al-Farabi y Avicena según la cual la Causa Primera mueve las esferas celestiales y de la que emana eternamente una inteligencia primera; y de ésta emanan otra serie de inteligencias: al final se encuentra el Entendimiento Agente, último peldaño de la jerarquía incorpórea. En el Gran Comentario a la Metafísica, la Causa Primera aparece como causa de todas las inteligencias incorpóreas, en cuanto que cada una de ellas tiene el pensamiento de la Causa Primera. Interpretando a Aristóteles afirma que la Causa Primera - pensamiento que se piensa eternamente a sí mismo- es causa de la existencia, y no solamente Motor de Universo. El Intelecto Agente, por su parte, aparece también como causa del mundo sublunar, pero no causa de la existencia - a diferencia de sus predecesores, sino sólo de las formas sustanciales naturales. De esta manera se observa la relación (pero no identificación) entre la Causa Primera y el Intelecto Agente Universal.

Sin embargo, en los últimos escritos de Averroes parece haber una cierta evolución en la doctrina del Entendimiento Agente, puesto que ya no se presenta como principio de la existencia, sino tan sólo del conocer del hombre, porque su función consiste únicamente en actualizar al entendimiento potencial. De esta manera, la Causa Primera es causa tanto del ser como de la forma natural, relegando al Entendimiento Agente a su función meramente gnoseológica ${ }^{3}$. Así parece aproximarse más a la postura genuinamente aristotélica, separándose de la tradición neoplatónica legada por sus predecesores árabes.

1 Cfr. Higuera Rubió, J. G., «Honor y Dialéctica: sobre la representación caballeresca de Ramón Llull en el Breviculum de Tomás Le Myésien, Ramón Llull caballero de la fe, El arte luliana y su proyección en la Edad Media A. Fidora y J. G. Higuera (eds.), Cuadernos de Anuario Filosófico, Serie de Pensamiento español, n. 17, Pamplona, Servicio de Publicaciones de la Universidad de Navarra, 2001, pp. 81-109.

2 Cfr. Munk, S., Mélanges de Philosophie juive et arabe, Paris, Vrin, 1955, pp. 442-453.

3 Cfr. Davidson, H. A., Alfarabi, Avicenna, and Averroes on Intellect. Their Cosmologies, Theories of the Active Intellect, and Theories of Human Intellect, New York, Oxford University Press, 1992, p. 256. 
En la metafísica de Averroes se afirma la doctrina del Entendimiento Agente Único y separado, pero se añade la doctrina del entendimiento material único. En el Gran Comentario al De Anima se dice que el Entendimiento Agente es una sustancia incorpórea, trascendente al alma humana individual, cuya misión consiste en iluminar las imágenes sensibles que son recibidas por el entendimiento posible o material, que es también un principio espiritual único receptor de formas inteligibles ${ }^{4}$. Ambos entendimientos (el agente y el posible) son sustancias eternas que existen fuera del alma individual ${ }^{5}$; son sustancias separadas, comunes a toda la humanidad y conectados con cada hombre mediante el conocimiento sensible de las imágenes. Cuando los datos sensibles entran en contacto con el entendimiento posible, son iluminados por el Entendimiento Agente, de modo que el contenido universal es separado de sus condiciones individuales, produciéndose los conceptos abstractos que son recibidos en el entendimiento posible $^{6}$. En el alma humana individual existe un entendimiento pasivo (una cierta vis cogitativa unida a los órganos corporales sensitivos), y un entendimiento teórico o habitual, que es fruto de la acción del entendimiento pasivo. Éstos dos entendimientos (el pasivo y el habitual) son individuales, y debido a su unión con el cuerpo, perecederos.

Averroes atribuye la diversidad de pensamientos subjetivos a la distinta experiencia sensible y a la diferente imaginación de cada uno. La compleja explicación averroísta puede ser entendida, siguiendo a Cruz Hernández, como un intento de salvar la existencia de una ciencia objetiva frente al subjetivismo: «Mientras existan hombres, quiere decir Averroes, tendrán que pensar del mismo modo, tendrán un mismo punto de contacto con la verdad objetiva. Es cierto que mi perspectiva de la verdad - grande o pequeña, científica o vulgar- morirá conmigo, con mis órganos de los sentidos, con mi sistema nervioso, pero la verdad que haya en ella será eterna»? ${ }^{7}$.

A pesar de la separación del Entendimiento Agente y Posible con respecto al alma humana individual, existe una posibilidad de unión del entendimiento pasivo individual con el Intelecto Agente universal, y de esa manera se obtiene la inmortalidad ${ }^{8}$. Pero la persona individual, como tal, no pervive, porque nada de lo que pertenece al hombre individual es capaz de sobrevivir al cuerpo 9 . «l contacto entre el Intelecto agente separado y el entendimiento pasivo del individuo engendra una receptividad con respecto a lo inteligible que no es más que el Intelecto Agente mismo particularizándose en un alma, como la luz de un cuerpo. El Intelecto Agente está separado; no pertenece al individuo, ni tampoco la luz que lo ilumina. La inmortalidad es sólo del Intelecto Agente» ${ }^{10}$.

Éste viene a ser el punto central del problema para la interpretación de la escolástica cristiana de la doctrina del entendimiento agente. San Alberto Magno, en su labor especulativa debía reelaborar las aportaciones del aristotelismo y de los intérpretes árabes si quería seguir manteniendo la centralidad de la doctrina del entendimiento agente. Pero para asegurar la inmortalidad personal era preciso mantener el entendimiento agente como una parte del alma humana individual.

4 Cfr. Averroes, Commentarium magnum in Aristotelis De Anima, ed. F. S. Crawford, Massachusetts, Cambridge, 1953, nn. 18-21; Davidson, H. D., o. c., p. 316.

$5 \quad$ Ibid.,p. 319.

6 Cfr. Kuksewicz, Z., «The potential and the agent intellect», The Cambridge History of Later Medieval Philosophy, Cambridge University Press, 1982, pp. 595-596.

7 Cruz Hernández, M., La Filosofía árabe, Madrid, Revista de Occidente, 1963, p. 319.

8 Cfr. De Libera, A., La philosophie médiévale, (2a ed.), Paris, P.U.F., 1995, pp. 170-171.

9 Cfr. Averroes, In III De Anima, nn. 18-19.

10 Gilson, E., La Filosofia en la Edad Media, (2a ed.), Madrid, Gredos, 1965, p. 342. 


\section{EL ENTENDIMIENTO AGENTE PERSONAL EN EL PENSAMIENTO ALBERTINO}

Penetrar en la obra y el pensamiento filosófico de San Alberto Magno no es tarea senci1la. Ya ha sido puesto de relieve en numerosas ocasiones la dificultad para determinar la doctrina propia del Maestro de Colonia diferenciándola de aquellas doctrinas que está interpretando. Otras veces es preciso distinguir diversas etapas de su pensamiento. $Y$ todo esto sin perder de vista el carácter asistemático, y en ocasiones, aparentemente ecléctico de sus escritos $^{11}$.

Los filósofos cristianos no podían aceptar de manera acrítica la doctrina árabe del entendimiento agente. La impronta personalista cristiana hacía necesaria una interpretación de la doctrina aristotélica acorde con la pervivencia personal del alma humana en la otra vida. No cabía seguir afirmando la inmortalidad del alma sólo disolviéndose en la unión con el Intelecto Agente Universal, tal como parece seguirse de los textos de Avicena o Avempace. Alberto Magno lo sabía, y se propuso realizar una exégesis cristiana de la doctrina aristotélica del entendimiento agente ${ }^{12}$.

Creo oportuno señalar, como ya indicó Salman, que la reflexión albertina sobre el entendimiento agente (recogida especialmente en el De Unitate Intellectus contra Averroem) no se dirige sólo, ni principalmente, contra las tesis averroístas, sino más bien a toda la interpretación árabe acerca del carácter «separado» del Entendimiento Agente único y universal para salvaguardar la inmortalidad del alma individual después de la muerte ${ }^{13}$. Por eso se puede afirmar con De Libera que la psicología albertina nace como un diálogo intelectual con Averroes ${ }^{14}$, más que como una abierta confrontación con su doctrina. Esto podría explicar en parte las oscilaciones a la hora de juzgar los comentarios de Averroes a la obra aristotélica ${ }^{15}$. En efecto, a lo largo de la primera exposición que Alberto Magno realiza de la psicología aristotélica sobre el alma manifiesta su desacuerdo con Al-Farabi, Algazel y Avicena porque piensan que el entendimiento agente es una sustancia separada, y por lo tanto inmortal y eterna, pero no se multiplica en cada uno de los individuos humanos ${ }^{16}$. Para Alberto Magno, el entendimiento agente no es en modo alguno una inteligencia separada, sino que es realmente una parte del alma humana individual. Lo que resulta sorprendente es que aduzca la autoridad de Averroes en apoyo de su tesis, cuando el filósofo cordobés de manera explícita afirma precisamente lo contrario ${ }^{17}$.

En el comentario al De Anima, escrito años después, Alberto ha corregido ya su interpretación de Averroes. Con respecto a la doctrina del entendimiento agente, afirma que está de acuerdo con el Comentador en lo que se refiere a la operación y naturaleza del mismo, pero

11 Aunque quizás parezca excesiva la descrippción de De Libera del pensamiento de San Alberto: «Enciclopédico y confuso, teólogo fascinado por la filosofía, pero filósofo poco original; experto en digresiones que niegan la proposición inicial y retardan la conclusión; pródigo en análisis donde haría falta una síntesis; inútil e incierto cuando se requiere una respuesta clara, Alberto será más historiador que filósofo, complicándose en contradicciones por el mero placer del detalle, perdiéndose en lo anecdótico por la sola razón de ser completo». De Libera, A., Albert le Grand et la philosophie, Paris, J. Vrin, 1990, p. 7.

12 Crr. Mattos, G. de, «L'intellect agent personnel dans les premiers écrits d'Albert le Grand et de Thomas d'Aquin», Revue néoscolastique de philosophie, 43 (1940), pp. 145-161.

13 Cfr. Salman, D., «Albert le Grand et l'averroïsme latin», Revue des sciences philosophiques et théologiques 24 (1935), pp. 38-65.

14 Cfr. De Libera, A., Albert le Grand et la Philosophie,, p. 215.

15 A este respecto puede consultarse la comunicación de Blasberg, R., «El averroísmo según el tratado $D e$ Tempore de Alberto magno», Averroes y los averroísmos. Actas del III Congreso Nacional de Filosofia Medieval, (Jorge M. Ayala, ed.), Sociedad Española de Filosofía Medieval, Zaragoza 1999, pp. 267-275.

16 Cfr. Summa de Creaturis, q. 53, a. 1 y a. 3; q. 59, a. 1.

17 Cfr. Miller, R., «An Aspect of Averroes Influence on St. Albert», Mediaeval Studies, 16 (1954), pp. $57-71$. 
no en lo que atañe al Intelecto Agente Universal, porque para el Coloniense, el entendimiento agente es una parte del alma humana individual: se trata ciertamente de una potencia activa del alma que informa al intelecto posible o paciente, que se corresponde con la potencia pasiva del alma intelectual ${ }^{18}$. En otras obras se afirma también de manera explícita que es un principio que pertenece sustancialmente al alma ${ }^{19}$; un principio inmanente al alma humana ${ }^{20}$. Se trata de una potencia activa que siempre se encuentra en acto, pero no puede identificarse con el alma humana de la cual forma parte, puesto que hay diversas funciones que lleva a cabo el alma humana que pertenecen a la vida vegetativa y sensitiva, pero que el alma intelectual asume. De esta manera es preciso reconocer una pluralidad de formas sustanciales en el hombre ${ }^{21}$.

San Alberto Magno afirma que entre el entendimiento agente y entendimiento posible (ambos personales) se da una distinción real. El Coloniense parece ser el primero que de manera explícita afirma tal distinción real proponiendo cuatro argumentos ${ }^{22}$ :

$1^{\circ}$ ) porque el entendimiento agente es motor, mientras que el posible es movido;

$\left.2^{\circ}\right)$ porque el alma está en acto por el intelecto agente, pero en potencia por el intelecto posible;

$\left.3^{\circ}\right)$ porque el alma es agente según el entendimiento agente, pero por el intelecto posible es paciente;

$\left.4^{\circ}\right)$ porque el alma es susceptible de recibir todas las cosas gracias al intelecto posible, mientras que por el intelecto agente no es susceptible de recibir nada ${ }^{23}$.

De esta manera el Coloniense definirá el entendimiento agente como «potencia y el principio activo de los inteligibles, y por eso dice el Filósofo que es el intelecto que hace todas las $\cos a s{ }^{24}$ (a diferencia del intelecto pasivo que «se hace» todas las cosas).

Antes de continuar adelante sería preciso aclarar terminológicamente los distintos sentidos que el término intellectus adquiere en la obra albertina. El entendimiento agente actualiza mediante las especies inteligibles al entendimiento posible que antes de recibir las especies es como una «tabla rasa en la que nada hay escrito» ${ }^{25}$. El entendimiento posible (intellectus possibilis), una vez actualizado, se constituye como intellectus adeptus, que a su vez es preciso distinguir del intelecto como hábito (intellectus ut habitus). En efecto, el entendimiento agente tampoco es un hábito, sino más bien un acto que incesantemente actúa. Según Alberto Magno es preciso distinguir dos operaciones del entendimiento agente:

$1^{\circ}$ ) Abstraer las formas inteligibles que se encuentran en las especies sensibles sólo en potencia;

$2^{\circ}$ ) Iluminar al intelecto posible, como la luz se comporta con respecto a lo diáfano ${ }^{26}$.

18 «Per hoc enim videtur nobis, nec de hoc dubitamus, quin intellectus agens sit pars et potentiae animae, sed tunc dicentes eum esse partem...s: Alberto Magno, De Anima, edidit Clemens Stroick, en Opera Omnia, Tomus VII, Pars I, Monasterii Westfalorum in Aedibus Aschendorff 1968, III, 3, 11, p. 221, 25-29.

19 Cfr. II Sententiarum, d. 8, a. 10, c.;

20 Cfr. Summa de creaturis, II, q. 8, a. 2, ad 5.

21 Cr. Summa Theologiae, P. II, tract. XII, q. 70, memb. 11, sed contra. Vol. 33, p. 22, col. 1.

22 Sobre la distinción real cfr. Browne, M., "Circa intellectum et eius illuminationem apud S. Albertum Magnum», Angelicum 9 (1932), pp. 190-196.

23 Cfr. Summa de creaturis, P. II, q. 55, a. 4, partícula 2.

24 «(..) potentia et principium activum intelligibilium, et propter hoc dicit Philosophus quod est intellectus quo est omnia facere». Ibid., q. 56, a. 2, sol.

25 Cfr. Summa Theologiae, P. II, tract. XV, q. 77, memb. II, sol.

26 «duo sunt opera agentis, quorum unum est abstrahere formas intelligibiles, quod nihil aliud est nisi facere eas simplices et universales. Secundum est illuminare possibilem intellectum, sicut lumen se habet ad diaphanum, quod oportet quod species universalis quamdiu est universalis, semper sit in lumine agentis: et ideo quando recipitur in possibili intellectu oportet quod in lumine agentis recipiatur: et ideo oportet possibilem illuminari lumine intellectus agentis». De Anima, III, tract. II, c. 29, vol. 5, p. 366, col. 1. 
Es preciso aclarar que no se trata de dos funciones yuxtapuestas sino más bien necesariamente conectadas entre sí. En efecto, el entendimiento agente actúa de modo análogo a la luz corporal, pues «así como la luz corpórea realiza dos actos en orden a hacer visible en acto lo que era visible en potencia (uno es abstraer los colores y elevarlos al ser espiritual; otro consiste en iluminar el medio, lo cual los hace aptos para la vista), de modo similar la acción del intelecto agente es doble: por un lado abstrae los inteligibles y les da el ser inteligibles según la especie inteligible; por otro lado ilumina al intelecto posible para que resplandezcan en él las especies inteligibles» ${ }^{27}$. En otras palabras, San Alberto parece sostener que el inteligible y la luz del entendimiento agente forman el objeto inteligible; es decir que el entendimiento agente es tanto la forma de lo inteligible como del entendimiento posible ${ }^{28}$.

En la abstracción se obtiene una forma universal que debe ser constantemente iluminada por la luz del entendimiento agente en orden al ser inteligible; pero también el intelecto agente «acompaña» esta forma hasta el entendimiento posible. El entendimiento posible es entonces informado no sólo por la especie inteligible, sino también, al mismo tiempo y en una unidad con el objeto inteligible, por la luz del mismo intelecto agente ${ }^{29}$. Así pues, el intelecto agente es forma del posible, y al mismo tiempo es causa eficiente de la inteligibilidad ${ }^{30}$.

\section{LA SEPARABILIDAD DEL ENTENDIMIENTO AGENTE PERSONAL}

A continuación intentaré determinar el sentido preciso de la afirmación aristotélica acerca de la «separación» del entendimiento agente, según la doctrina albertina. ¿Qué significa exactamente que el entendimiento agente es un entendimiento «separado»? ¿se trata de un principio de conocer «separado» del alma individual, y por lo tanto de un principio extrínseco a ella? Según Averroes, la separación indicaría la independencia con respecto al alma individual, porque si el entendimiento agente estuviera unido al hombre, que por naturaleza es mortal y corruptible, el entendimiento agente se corrompería con él, lo que va en contra de la doctrina aristotélica de la eternidad e impasibilidad del entendimiento agente.

El problema central lo constituye el hecho de que si una sustancia está unida a la materia, su operación no puede separarse de la materia. «Este argumento se basa en uno de los princi-

27 Summa Theologiae, P. II, tract. IV, q. 14, memb. III, art. 2 particula 1, ad 1 ${ }^{\mathbf{a}}$, vol 32, p. 180, col. 1-2.

28 «Ita etiam est de formis imaginatis et in sensitivis acceptis a lumine intellectus agentis. Et ideo non accipiuntur ab intellectu possibili, nisi separatae sint ab eadem luce quae est actus et perfectio possibilis». De Unitate intellectus, c. 6, IX, 464; «Lux agentis quae est actus possibilis, est actus intelligibilis». Ibid, c. 7, ad 27; IX, 472; «Lumen quod est actus intellectus agentis, est forma et intellectus possibilis et eius quod intelligitur». De Int. et Int., II, 1,5 ; IX, 510 .

29 «Ex his autem facile adverti potest, quod duo sunt opera agentis, quorum unum est abstrahere formas intelligibiles, quod nihil aliud est nisi facere eas simplices et universales. Secundum est illuminare possibilem intellectum, sicut lumen se habet ad diaphanum, quod oportet quod species universalis quamdiu est universalis, semper sit in lumine agentis: et ideo quando recipitur in possibili intellectu, oportet quod in lumine agentis recipiatur: et ideo oportet possibilem illuminari lumine intellectus lumine intellectus agentis. Similiter autem possibilis dupliciter habet comparationem: comparatur enim ad agentem sicut completus suo, et comparatur ad formas ex phantasiis elicitas sicut motus et formatus ab eis». De Anima, III, 2, 19; V, 366; «Et ideo in omnibus [intelligibilibus] accipit continue intellectus possibilis lumen agentis». Ibid., 3,$11 ; \mathrm{V}, 386$.

30 Cfr. Summa de creaturis, P. II, q. 55, art. 6, sol. vol. 35, p. 475, col 2-476, col. 1. Un tratamiento más detallado de la distinción y diversas funciones del entendimiento agente y posible, con textos de San Alberto, se puede encontrar en LAUER, R. Z., «St. Albert and Theory of Abstraction», The Thomist, 17 (1954), pp. 69-83; KENNEDY, L., A., «The Nature of the Human Intellect according to St. Albert the Grant», The Modern Schoolman, 37 (1960), pp. 121-137. Más reciente es el estudio comparativo entre las teorías del conocimiento albertina y tomista de DEWAN, L., «St AIbert, St. Thomas, and Knowledge», American Catholic Philosophical Quarterly, 70 (1996), pp. 121-135. 
pios fundamentales de la metafísica: agitur sequitur esse: la forma de actuar (agere) depende del modo de ser (esse). Así pues, si el esse depende la materia, así también debe depender su actividad (agere) y, a la inversa, si su actividad está separada de la materia, así debe estarlo su ser (esse). Ante este argumento metafísico, todo lo que se puede decir es que los hechos demuestran que el hombre es único en toda la creación: posee un alma espiritual que informa el cuerpo dándole existencia humana, $\mathrm{y}$, al mismo tiempo, tiene operaciones, tales como pensar, que trascienden el órgano que utiliza, el cerebro. Esta trascendencia demuestra que el alma es separable e inmortal, pero no que está separada aquí y ahora» ${ }^{31}$. En consecuencia, la separabilidad del entendimiento agente a la que alude Aristóteles no implica que éste posea una existencia independiente del hombre particular, es decir de la persona, sino que la separación de lo material proviene de su independencia con respecto al cuerpo en el orden del entender.

Alberto Magno dedica particular atención a este punto en su tratado acerca De la Unidad del entendimiento contra los averroístas ${ }^{32}$. Para el Coloniense, el entendimiento agente es una virtus o potencia del alma individual; brota de ella en orden a realizar el acto de conocimiento intelectual. Si su ser es relativamente independiente del cuerpo, su obrar también lo será.

Paralelamente, la afirmación aristotélica acerca de la «eternidad» del entendimiento agente, es preciso interpretarla de modo correcto. En sentido estricto, sólo la Causa Primera es eterna, en la que no hay comienzo ni fin precisamente porque existe desde siempre. No obstante se puede afirmar que el entendimiento agente personal es «eterno» en el preciso sentido de que tiene un origen supratemporal ${ }^{33}$. De hecho, no posee un término temporal, pues la inmortalidad del alma humana descansa en la perennidad del intelecto agente personal (como veremos más adelante), aunque su comienzo está marcado por un acto creador de Dios en el tiempo.

\section{DIOS Y EL ENTENDIMIENTO AGENTE UNIVERSAL}

Con lo expuesto hasta el momento, el pensamiento de San Alberto nos parece original y liberado del lastre de las interpretaciones árabes en la medida en que se ha desligado de la creencia de un entendimiento agente extrínseco al alma humana. Sin embargo, la complejidad de la doctrina albertina acerca del entendimiento agente no acaba de dejar de lado algunos resabios neoplatónicos procedentes del mundo árabe. En efecto, al mismo tiempo que subraya la necesidad del entendimiento agente personal, afirma la existencia de un Intelecto Agente Universal, principio del conocimiento humano, y más radicalmente, causa del acto del ser del alma individual: en consecuencia cabría identificarlo con Dios mismo.

Como ha sido puesto de relieve por los medievalistas que han estudiado la obra albertina, su teoría del conocimiento no deja de ser deudora de la iluminación agustiniana. Se trata de una cuestión debatida el determinar hasta qué punto se hace compatible con la teoría de la abstracción aristotélica, pero de la lectura de los textos se desprende la conclusión de que Alberto Magno no logra superar una tendencia al sincretismo entre la iluminación agustiniana (la llevada a cabo por el Entendimiento Agente Universal, desde fuera del alma humana individual) y la abstracción aristotélica. Ambas formas de conocimiento se dan en el hombre de modo complementario, como ha apuntado Kennedy: «Podemos concluir que San Alberto sostiene tanto en sus obras filosóficas como teológicas que el entendimiento humano debe ser iluminado por Dios y los ángeles en algo que pertenece a su conocimiento natural —esto es, en la metafísi-

31 Weisheipl, J. A., Tomás de Aquino. Vida, obras, doctrina, Pamplona, EUNSA, 1994, p. 321.

32 Cfr. Alberto Magno, Libellus De Unitate Intellectus contra Averroistas, edidit Alfonsus Hufnagel, en Opera Omnia, Tomus XVII, Pars I, Monasterii Westfalorum in Aedibus Aschendorff 1975, pp. 1-30.

33 Cfr. Craemer-Ruegenberg, I., Alberto Magno, Barcelona, Herder, 1985, pp. 85-96. 
ca y en el conocimiento de las sustancias separadas-y que tal iluminación es esencialmente distinta de la abstracción, a la cual precede» ${ }^{34}$.

La identificación entre Dios y el Entendimiento Agente Universal como principio extrínseco del entendimiento humano se afirma en numerosos pasajes de su obra. Así aparece, por ejemplo, en el comentario al Primer Libro de las Sentencias: «la luz del intelecto agente no basta por sí misma [para conocer] si no es a través de la aplicación de la luz del Intelecto Increado, como se aplica el rayo de sol a la estrella» ${ }^{35}$. Ciertamente la iluminación propuesta por San Alberto no se identifica sin más con la doctrina agustiniana y aviceniana. En la gnoseología aviceniana las formas universales son comunicadas al intelecto posible humano por un Intelecto Agente separado del alma humana individual. Por su parte, en la iluminación agustiniana, el Dios cristiano comunica a la mente humana no el contenido del conocimiento (es decir, las ideas universales) sino la verdad de sus juicios, lo que en términos de Gilson llamaríamos la «Verdad-Iluminación» ${ }^{36}$. En la iluminación albertina la Luz de Dios (Entendimiento Agente Universal) no confiere directamente el conocimiento en cuanto a su contenido, sino que refuerza el poder del entendimiento agente individual ${ }^{37}$. A lo largo de la obra del Coloniense se da una evolución en el modo de complementar el conocimiento abstractivo y la iluminación, pero en última instancia, y es lo que nos interesa subrayar, Dios (Entendimiento increado o Intelecto Agente Universal) se encuentra en la base como fundamento y garantía del conocimiento humano.

Pero el Entendimiento Agente Universal no sólo es principio del conocer, sino también del ser, en la medida en que no sólo comunica la luz del conocimiento, sino el mismo ser a la criatura. En el comentario al Liber de Causis, el Coloniense trata acerca del Principio de todo ser y de todo inteligir: la Causa Primera que no es otra que el Entendimiento Agente Universal. El Entendimiento Primero, es decir, el Intelecto Agente universal «es totalmente inmaterial y es la primera razón de las cosas hechas y de los pensamientos» ${ }^{38}$. Poco antes había afirmado que «la luz del entendimiento agente es la causa de la existencia de todo aquello que es» ${ }^{39}$. Encontramos de nuevo el puesto preeminente asignado por la filosofía árabe al Entendimiento agente: no sólo como causa (extrínseca) del conocer humano, sino también de ser de la criatura ${ }^{40}$.

De esta manera, el Intelecto Agente Universal vendría a identificarse con Dios mismo, fuente inagotable de ser y origen del ser de las cosas. ¿Cómo representar a este primer principio radical de todas las cosas? Alberto Magno acude a la analogía del Sol, fuente y origen de la luz, gracias a la cual, todo lo demás está iluminado. Lo interesante de la analogía de la luz es comprobar cómo se compara al ser: el Sol (imagen del Primer Principio radical de todas las

34 Kennedy, L. A., «St. Albert the Great's Doctrine of Divine Illumination», en The Modern Schoolman, 40 (1962), p. 35.

35 «quod lux intellectus agentis non sufficit per se, nisi per applicationem lucis intellectus increati, sicut applicatur radius solis ad radium stellae», In I Sententiarum, d. 2, a. 5, sol.; vol. XXV, 59-60. Cfr. también d. 46, a. 19, sol.; vol. XXVI, 462.

36 Gilson, E., «Les sources gréco-arabes de l'agustinisme avicennissant», Archives d'Histoire doctrinale et littéraire du Moyen Age», 4 (1929), p. 107.

37 «Therefore the light of illumination either strengthens the power of the agent intellect or gives extra illuminationon the object from wich abstractionis made or does both; it does not confer knowledge directly, howewer». Kennedy, L. A., «St. Albert's Doctrine...», p. 27.

38 «... activum intellectum, qui omnino est sine materia et est prima ratio factorum et scitorum,...». Alberto Magno, De Causis et processu universitatis a Prima Causa, en Opera Omnia, Tomus XVII, Pars II, Monasterii Westfalorum in Aedibus Aschendorff 1993, pp. 30, 46.

39 Ibid. 26, 53-54.

40 Un estudio claro y riguroso de la doctrina albertina sobre la causalidad puede encontrarse en Molina Díez, E., «Movens-Efficiens-Agens: la fundamentación causal en San Alberto Magno», Excerpta e Dissertationibus in Philosophia 8 (1998), pp. 277-348. 
cosas) es la fuente y el origen del ser de las cosas. La metáfora de la luz adquiere así un valor central no sólo en un contexto gnoseológico, sino también ontológico.

Al igual que sus contemporáneos escolásticos, San Alberto afirma que en Dios se identifican la esencia y el acto de ser (es un ser absolutamente simple, donde no se da ningún tipo de composición), mientras que en las criaturas estos dos principios se distinguen entre sí: la esencia limita y determina el acto de ser, para que sea esto y no otra realidad. Aquí radica la diferencia metafísica entre Creador y criaturas. En el Coloniense esta distinción se establece con los términos quod est y quo est ${ }^{41}$. En la Summa de creaturis, en el tratado II (sobre el hombre), ya había apuntado a la distinción real entre esencia y acto de ser en correspondencia con la distinción entre entendimiento agente y posible: «El entendimiento agente es la parte del alma que fluye de aquello por lo que es (quo est), o acto; el [entendimiento] posible es la parte del alma que fluye de lo que es (quod est) o potencias ${ }^{42}$.

Puede ser oportuno ahondar en la metáfora albertina del Sol aplicada a Dios. En el Sol se identifica el ser y la esencia (al igual que sucede en Dios), mientras que en los seres creados (iluminados por la luz del sol) el quod est, el principio esencial de cada cosa, no se identifica con el actus essendi, que depende del Primer principio ${ }^{43}$. El Entendimiento Agente Universal se diferencia del particular en que éste se encuentra limitado y determinado por un principio esencial (id quod est); pero el entendimiento agente particular recibe su ser y su luz del primer principio superior ${ }^{44}$.

Sería preciso una mayor atención a otros textos de la obra albertina, pero de los aducidos hasta el momento parece deducirse que la luz del entendimiento agente es el mismo acto de ser, que se encuentra imparticipado en Dios, Causa primera de todas las cosas, mientras que en las criaturas el acto de ser se encuentra limitado y determinado por su esencia. En las criaturas espirituales la distinción real entre quod est (esencia) y quo est (acto de ser) parece corresponderse con la distinción real que se establece entre entendimiento agente (individual) y entendimiento paciente. Esta es la concepción que parece desprenderse de otros textos de la Summa de creaturis en donde se apunta que la diferencia que se establece entre el entendimiento agente y posible es la misma que se establece ente el esse y el posse ${ }^{45}$.

Más explícito es el siguiente texto en el que trata de la naturaleza del alma humana: «los principios de la esencia del alma intelectiva son lo que es y aquello por lo que es; y así como en aquello 'por lo que es' (id quo est) se funda el entendimiento agente, así también en 'lo que

41 Para la distinción entre quod est y quo est cfr. Baldner, S., «St. Albert the Great on the Union of the Human Soul and Body», en American Catholic Philosophical Quarterly, 70 (1996), pp. 104-108.

42 «Intellectus agens est pars animae fluens ab eo quo est, sive actu; possibilis autem pars animae est fluens ab eo quod est, sive potentia». Summa de creaturis, II (De Homine), q. 55, a. 3. (De. Par. 35, p. 466).

43 «E omnibus his relinquitur, quod omnia quae sunt in universitate mundi, sint ab eo quod est necesse esse et quod ipsum nullo modo sit vel possit esse ab alio neque secundum esse neque secundum 'id quod est' neque secundum intellectum et quod omnia alia eo quod in unoquoque eorum aliud sit esse et 'id quod est', necesse est esse ab illo et quod ipse est fons et origo omnium quae sunt. Cuius exemplum est, quale possumus invenire, - perfectum enim exemplum illius nullo modo invenitur-sicut si dicamus, quod sol non est nisi lux et quod lux est sibi esse 'quod est'. Tunc enim omnia lucentia et illustrata et colorata sunt per hoc quod sol emittit lumen suum in ea». De Causis et processu universitatis a Prima Causa, Tomus XVII, Pars II, Monasterii in Aedibus Aschendorff 1993, pp. 23-24. Acerca de Dios como plenitud de ser y de luz, cfr. Sweeney, L., «Esse primum creatum in Albert the Great's Liber de Causis et processu universitatis», The Thomist, 44 (1980), pp. 599-646.

44 «i autem hoc modo primum principium dicatur esse ut agens intellectus, non erit univoce agens cum intellectu, qui in nobis est, vel cum aliquo, qui in ordine determinato est. Omnis enim intellectus agens ordinis determinati per illustrationem super se factam agens est et particulariter agens est et non de se secundum 'id quod est' agens est, quia non secundum 'id quod est' agere potest nec in id quod ante se est, agere potest, sed potius agit secundum id quod se habet ad antecedentem intellectum, et secundum illud esse, quod super ipsum et in ipsum emanat ab intellectu ordinis se antecedentis». Ibidem, p. 26, 67-78.

45 Cfr. Alberto Magno, Summa de creaturis, ed. Pétrus Jammy, Lyon, 1651, q. 53, p. 256/1. 
es' (id quod est) se funda el entendimiento posible» ${ }^{46}$. Y en el Comentario al Libro dé las Sentencias, se afirma la tesis según la cual «el entendimiento agente se sigue del alma según su esse mientras que el entendimiento posible se sigue del alma según su esencia» ${ }^{47}$. Y en el comentario al libro De Anima, al tratar acerca de la naturaleza del entendimiento agente afirma: «Una cosa es la forma de la luz y otra cosa es aquello en lo que la luz se recibe y permanece (...); y por esto del alma fluyen dos virtudes: una es el entendimiento agente, que está causado por la misma luz recibida, y otra es el entendimiento posible, que está causado por aquello en lo que la luz es recibida» 48 .

Esta concepción le permite al Coloniense argumentar en favor de la inmortalidad del alma intelectiva, ya que si el acto de ser es el mismo entendimiento agente, éste permanece siempre, y es eterno e incorruptible: «el principio de la inmortalidad del entendimiento posible se da gracias al entendimiento agente, ya que su ser es por el agente ${ }^{49}$. Y en la Suma Teológica, apunta que todos los filósofos pusieron 'en el entendimiento agente la raíz de la inmortalidad del alma ${ }^{50}$.

\section{LA MÍSTICA ALBERTINA}

La centralidad de la doctrina expuesta con anterioridad apunta más allá de una mera disquisición teórica o abstracta. Tanto para los filósofos (y teólogos) árabes como para San Alberto Magno la doctrina del entendimiento agente posee una importancia decisiva para la vida humana. La felicidad se cifra, también en la doctrina albertina, en la unión eterna con el Entendimiento Agente Universal que es Dios.

Como resultado de la obra de los comentadores griegos, los filósofos árabes recibieron a un Aristóteles neoplatonizado. De hecho, se atribuyeron al Estagirita muchas obras en las que se mezclaban elementos peripatéticos y neoplatónicos: entre esas obras, se encontraba el Liber de Causis, de enorme influencia en la filosofía medieval. Para los comentadores árabes, el Intelecto Agente ocupa un lugar privilegiado en su cosmovisión metafísica. Además de la función gnoseológica (principio del conocimiento intelectual) posee también una función ontológica (principio del ser de las cosas); y aún cabe asignar al Entendimiento Agente una tercera función que podríamos denominar «religiosa» 0 «mística» en cuanto que relaciona el alma humana individual con la divinidad. En efecto, para el pensamiento árabe la felicidad humana consiste en la unión mística con el Intelecto Agente. El alma humana individual, desaparece en la unión con este principio de carácter divino, y en él pervive, de algún modo, por toda la eternidad ${ }^{51}$.

Como apuntó Renan en su ya célebre trabajo, los árabes añadieron a la doctrina aristotélica la unicidad del intelecto agente y la identidad del mismo con la última de las inteligencias

46 - (anima intellectiva) tamen principia suae essentiae sunt quod est atque quo est; atque sicut in quo est fundatur intellectus agens, ita in quod est fundatur intellectus possibilis». Ibidem, p. 259/2.

$47 \ll \mathrm{Si}$ enim anima consideretur in suo esse secundum quod est quaedam spiritualis substantia, sic (vires animae) consequentes sunt esse, et principiantur ab ipso esse et quod est, sicut ab ipso (esse) esset intellectus agens et ab ipso quod est intellectus possibilis et huiusmodi». Alberto Magno, In I Sententiarum, ed. Pétrus Jammy, Lyon 1651, d. III, a. 34, solutio; ad 2m. Cfr. Browne, M., «Circa intellectum et eius illuminationem apud S. Albertum Magnum», Angelicum, 9 (1932), p. 189.

48 «Quorum unum est forma lucis, et alterum est id in quo lux recipitur et stat, ut fiat ens aliquod mundi; et ab hoc esse animae fluunt duae virtutes, quarum una est intellectus agens, qui causatur ab ipse luce recepta, et alia est intellectus possibilis, qui causatur ab eo in quo lux recipitur». Alberto Magno, In III De Anima, c. 18, texto 17.

49 «...dicendum quod principium inmortalitatis possibilis intellectus est ab intellectu agente, sicut atque esse suum est ab agente». Alberto Magno, Summa de creaturis, q. 53, ad 3; 257/2.

50 Cfr. Alberto Magno, Summa Theologiae, ed. Pétrus Jammy, Lyon, 1651, tract. XV, q. 93, 448/2.

51 Cfr. Davidson, H. A., Alfarabi, Avicenna, and Averroes, on Intellect, pp. 7-219. 
mundanas ${ }^{52}$. Esta es básicamente la concepción de Al-Kindi (796-ca. 866), Al-Farabi (ca. 870950) y Avicena (980-1037). En Avempace (ca. 1070-1138), esta función «religiosa» aparece explícitamente al afirmar que el Intelecto Agente es el Principio Absoluto del pensar, del obrar y del ser, lo que vendría a ser la versión filosófica de Dios: «la felicidad última del hombre consistirá en la unión absoluta de los dos fundamentos, el yo-alma-intelecto y el del Intelecto Agente» ${ }^{53}$. Esta identificación con el Intelecto Agente llevará consigo la disolución de los individuos después de la muerte: de algún modo el individuo pervivirá en la otra vida, pero no de modo personal.

Ya hicimos alusión a la doctrina de Averroes en el que encontramos presente, junto al Intelecto Agente la doctrina del Intelecto posible único. Ambos. intelectos (el agente y el posible) son sustancias eternas que existen fuera del alma individual; son sustancias separadas, comunes a toda la humanidad y conectados en cada hombre por su cognición sensitiva individual. En el alma humana se dan también dos intelectos (el pasivo y el habitual) que son individuales, y por su unión con el cuerpo, perecederos. A pesar de la separación del Intelecto Agente y Posible con respecto al alma humana individual, existe una posibilidad de unión del intelecto material con el Intelecto Agente universal, y de esa manera se obtiene la inmortalidad ${ }^{54}$.

El pensamiento de San Alberto al respecto acusa la influencia averroísta, aunque purificada de aquello que parece incompatible con la pęrvivencia del alma humana individual después de la muerte. No resulta difícil establecer cierta similitud entre la propuesta de Averroes con la del Coloniense por lo que respecta a la concepción de la felicidad. La meta y objetivo del entendimiento humano se cifra en la unión y contemplación de las sustancias separadas, y más concretamente con el Entendimiento Agente. De hecho, el posible conocimiento de las sustancias separadas viene a ser la cuestión más importante de todas las que se refieren al alma ${ }^{55}$. Alberto Magno se pregunta si el entendimiento agente puede entender las sustancias separadas después de la muerte en lo cual consiste la felicidad: si eso fuera cierto la felicidad no podría ser alcanzada en la vida presente. Pero el Coloniense afirma que el intelecto puede llegar a conocer las sustancias separadas sólo a través de su conjunción con el Intelecto Agente divino. Esa conjunción puede darse de dos maneras: o bien el Intelecto Agente se encuentra con el intelecto posible como su causa productiva, o bien (lo cual es mucho más convincente) está conectado con él como su forma ${ }^{56}$. En este último caso el entendimiento humano alcanzará un alto nivel de felicidad y deificación. Contra los que arguyen que esta segunda manera de unión es imposible, San Alberto aduce la experiencia de las almas de los bienaventurados que conocen las cosas divinas y encuentran su más grande felicidad ahí. Habiendo alcanzado este estado del intellectus adeptus et divinus el hombre ha cumplido su función propia como ser racional, llegando a ser similar a Dios contemplando las sustancias separadas. Según Steel la manera en que Alberto Magno describe la felicidad suprema como contemplación, es sorprendentemente similar a la posición que defenderán años después algunos filósofos de la Facultad de Artes y que serán condenadas por peligroso «averroismo» ${ }^{57}$.

52 Cfr. Renan, E., Averroes y el averroismo, Madrid, Hiperion, 1992, p. 99.

53 Lomba Fuentes, J., «La búsqueda del fundamento en Avempace», Anuario Filosófico, 30 (1997), p. 605.

54 Cfr. De Libera, A., La philosophie médiévale, (2a ed.), Paris, P.U.F., 1995, pp. 170-171.

55 Cfr. De Anima, III, 3, 6; 215, II.19-20.

56 «Intellectus enim post mortem constat, quod intellegit separata. Et nos diximus in illa questione, quod nobis videbatur, quoniam nobis videtur, quod in hac vita continuatur cum agente formaliter, et tunc per agentem intelligit separata, quia aliter felicitas contemplativa non attingeretur ab homine in hac vita; et hoc est contra omnes Peripateticos, qui dicunt, quod fiducia contemplantium est ut formam attingere intellectum agentem». De Anima III, $3,12,224$, II.81-90.

57 Cfr. Steel, C., «Medieval Philosophy: an Impossible Projet? Thomas Aquinas and the Averroistic Ideal of Happiness», Miscellanea Mediaevalia, 26, Walter de Gruyter, Berlin 1998, p. 159. 
El eco de la doctrina albertina se deja sentir en la filosofía tardomedieval y renácentista, en abierto contraste con la doctrina tomista sobre la felicidad y la contemplación. De Libera sintetiza esa influencia en dos puntos: la teoría de la felicidad, fundada sobre una interpretación original de la noción del «intelecto adquirido» (intellects adeptus) que fue asumida por la mayor parte de los averroistas. El segundo punto se refiere a la concepción de la contemplación filosófica, que consiste en el conocimiento metafísico puramente intelectual consumándose en la vida presente una unión del hombre con Dios y a las sustancias separadas gracias al estudio y el ejercicio del pensamiento ${ }^{58}$.

Lo que podríamos denominar «pensamiento místico» de San Alberto dejó su huella en el pensamiento filosófico centroeuropeo, especialmente en la obra de Meister Eckhart y sus discípulos; de allí pasó a Nicolás de Cusa. En este campo, la escuela albertina se distancia cada vez más de los postulados de la escuela tomista llegando a configurar dos modos de pensamiento bien distintos entre $\mathbf{s i}^{59}$.

\section{CONCLUSIONES}

Llegados al final de nuestra exposición somos conscientes de no haber podido completar ni agotar las implicaciones que la doctrina de San Alberto Magno sobre la naturaleza y funciones del entendimiento agente. Ciertamente ese objetivo sobrepasa con mucho las limitaciones de este trabajo, si tenemos en cuenta, además, las graves dificultades hermenéuticas de la obra de Alberto Magno, tanto las que se refieren a los aspectos sincrónicos (descubrir el verdadero pensamiento albertino detrás de obras de distinto género literario, junto a la tendencia sincrética de su pensamiento), como diacrónicos (la datación de las obras albertinas en las que es posible advertir una evolución de su pensamiento).

No hemos podido aportar todos los textos del Coloniaense donde trata de este asunto, aunque pensamos haber proporcionado algunos textos significativos así como referencias bibliográficas que podrían ser el punto de arranque de una investigación más acabada. Así mismo, no ha sido posible analizar en profundidad las fuentes de su doctrina, y hasta qué punto acoge o rechaza las concepciones árabes del entendimiento agente, así como las diversas consecuencias de su planteamiento. Cabría plantearse, además, hasta qué punto se puede presentar un pensamiento internamente coherente sobre la doctrina del entendimiento agente en la obra de San Alberto: muchos puntos quedan en la oscuridad o resultan difícilmente conciliables entre sí.

No obstante, me atrevo a avanzar algunas conclusiones que son más bien una invitación a investigar más detenidamente la obra albertina. En primer lugar, la doctrina del Coloniense acerca del entendimiento agente presenta un intento de purificación de las propuestas árabes, pero sigue manteniendo la centralidad gnoseológica, ontológica y religiosa (en última instancia, también antropológica) de la naturaleza del intelecto agente. Alberto Magno y Santo Tomás depurarán más las atribuciones dadas al intelecto agente. En ambos autores se mantendrá, la centralidad del entendimiento agente en la gnoseología humana, pero en San Alberto se reformula en clave ontológica el Entendimiento Agente Universal como Causa Primera metafísica del ser, siendo el mismo ser subsistente (Ipsum Esse Subsistens). Por último, mientras que

58 De Libera, A., «Averroïsme Éthique et Philosophie Mystique. De la félicité intellectuelle à la vie bienheureuse», en Filosofia e Teologia nel Trecento.Studi in ricordo di Eugenio Nardi, (ed. Luca Bianchi), Féderation Internationale des Instituts d'Études Médiévales, Leuven-la-Neuve 1994, pp.34-36.

59 Acerca de la influencia de Alberto Magno y la diversificación de las escuelas tomista y albertina, cfr. Park, K., «Albert's Influence on Late Medieval Psychology», Albertus Magnus and the Sciences, Conmemorative Essays, (ed. James A. Weisheip1), Pontifical Institute of Medieval Studies, Toronto 1980, pp. 501-535. 
en la filosofía tomista, el intelecto agente pierde su sentido religioso al no identificarse con Dios mismo, la «mística» albertina tiende a identificar a Dios con el Intelecto Agente Universal: de la unión con ese Principio depende la felicidad humana.

Por otra parte, no deja de ser interesante el tratamiento albertino de la metáfora de la luz tanto en su vertiente gnoseológica (principio del conocimiento intelectual) como ontológica (principio del ser de las criaturas). En esta última, Alberto Magno apunta a la distinción entre esencia y acto de ser en el hombre en términos de entendimiento posible (que se correspondería a la esencia del hombre) y entendimiento agente (acto de ser humano). Se trata de una afirmación no desarrollada de manera sistemática: quizás únicamente San Alberto se propusiera apuntar una vía analógica de comparación entre estas dualidades. No deja por ello de poseer una indudable originalidad que podría seguir fecundando los estudios de filosofía medieval desde esta clave metafísica y antropológica.

En todo caso la centralidad del entendimiento agente en la Filosofía medieval, plasmada en la ingente obra albertina hace difícil concebir una adecuada comprensión del pensamiento medieval sin un tratamiento detenido de la doctrina del entendimiento agente, determinando su estatuto ontológico y sus funciones gnoseológicas.

José Angel García Cuadrado Facultad Eclesiástica de Filosofía

Universidad de Navarra 31008 Pamplona jagarcia@unav.es 